\title{
Synovial tissue macrophages: a sensitive biomarker for response to treatment in patients with rheumatoid arthritis
}

\author{
J J Haringman, D M Gerlag, A H Zwinderman, T J M Smeets, M C Kraan, D Baeten, \\ I B McInnes, B Bresnihan, P P Tak, on behalf of the OMERACT Special Interest Group \\ on Synovial Analysis in Clinical Trials
}

See end of article for authors' affiliations

Correspondence to: Professor P P Tak, Division of Clinical Immunology and Rheumatology, F4218, Academic Medical Centre/University of

Amsterdam, Meibergdreef 9, NL-1105 AZ

Amsterdam, The

Netherlands; p.p.tak@

amc.uva.nl

Accepted

21 November 2004

Published Online First

2 December 2004

Background: Previous work identified synovial sublining macrophage numbers as a potential biomarker for clinical efficacy in rheumatoid arthritis.

Objective: To investigate the association between changes in infiltration of synovial macrophages and clinical improvement after antirheumatic treatment.

Methods: 88 patients who participated in various clinical trials were studied. All patients underwent serial arthroscopy before initiation of treatment and after different time intervals. Immunohistochemical and digital image analysis were performed according to standardised procedures to detect changes in CD68+ synovial sublining macrophages in relationship to changes in the 28 joint count Disease Activity Score (DAS28). Statistical analysis was performed using one way analysis of variance, the independent samples $t$ test, linear regression, and the standardised response mean (SRM).

Results: For good, moderate, and non-responders, according to the DAS28 response criteria, there was a significant difference in the change in sublining macrophages (mean (SEM) cells $/ \mathrm{mm}^{2}-643(124),-270$ (64), and $-95(60)$, respectively; $p<0.0003)$. There was a significant correlation between the change in the number of macrophages and the change in DAS28 (Pearson correlation $0.874, p<0.01$ ). The change in sublining macrophages explained $76 \%$ of the variation in the change in DAS28 $(p<0.02)$. The sensitivity to change of the biomarker was high in patients treated actively (SRM $>0.8$ ), whereas the ability to detect changes in placebo treated patients was weak (SRM $<0.3$ ).

Conclusion: The results suggest that changes in synovial sublining macrophages can be used to predict possible efficacy of antirheumatic treatment.

$\mathrm{T}$ he recent increase in the development of a variety of new targeted treatments clearly raises the need for sensitive biomarkers, which could be used for selection during the development process. The acquisition of optimal tissue samples has been greatly enhanced by technological developments in needle arthroscopy. ${ }^{1}$ Reliable microscopic quantification of synovial inflammation has been facilitated by advances in computerised image analysis. By these means, sequential synovial biopsy specimens have recently been analysed in several clinical trials evaluating the effects of disease modifying antirheumatic drugs (DMARDs), biological treatments, and targeted small molecules. These studies suggested consistent associations between the rapidity and magnitude of both the clinical and immunohistological responses. No consensus, however, has previously emerged as to the optimal markers in tissues that are representative of disease activity or sensitive to change.

A prior cross sectional study in 62 patients with rheumatoid arthritis (RA) using stepwise multiple regression analysis showed that scores for local disease activity are particularly associated with the number of macrophages in the synovial sublining as well as the expression of macrophage derived cytokines. ${ }^{2}$ Recently, we conducted a randomised trial to try to answer the question of which feature in RA synovial tissue (ST) samples could be used as a biomarker for clinical efficacy in relatively small studies of short duration. ${ }^{3}$ Patients received either prednisolone according to the COBRA regimen ${ }^{4}$ or placebo for 2 weeks. ST samples were obtained before the start of treatment and at 2 weeks.
Twenty four immunohistological markers were investigated in this study. Each of the end points was statistically analysed using an analysis model of covariance. The model fitted included terms for treatment as a fixed effect and the baseline measurement as a covariate. The aim was to assess the treatment difference. This study identified sublining macrophages as the best biomarker associated with the clinical response to corticosteroids. ${ }^{3}$

The utility of CD68+ macrophages in the sublining layer as a candidate biomarker now requires to be tested across discrete interventions and kinetics. The objective of this study was to investigate the changes in this biomarker after different treatments and after different time intervals in relationship to the clinical response to treatment to validate the analysis of synovial macrophages in clinical studies.

\section{PATIENTS AND METHODS \\ Patients}

ST was obtained by arthroscopy under local anaesthesia at two different times from a clinically active wrist, knee, or ankle joint of each of 88 patients who fulfilled the American College of Rheumatology criteria for RA. ${ }^{5}$ Before each arthroscopy the 28 joint count Disease Activity Score

Abbreviations: DAS28, 28 joint count Disease Activity Score; DMARDs, disease modifying antirheumatic drugs; IL, interleukin; LEF, leflunomide; MTX, methotrexate; RA, rheumatoid arthritis; SRM, standardised response mean; ST, synovial tissue; TNF, tumour necrosis factor 
(DAS28) was calculated. ${ }^{6}$ All patients had active disease before initiation of treatment, measured by a tender and swollen joint count of at least six joints in combination with a raised erythrocyte sedimentation rate and/or $\mathrm{C}$ reactive protein and/or significant morning stiffness. All patients were included in clinical trials and the complete patient group comprised seven subgroups receiving distinct treatment regimens.

Fifteen patients who were DMARD naïve for at least 28 days started treatment with methotrexate (MTX), ${ }^{7}$ at $7.5 \mathrm{mg} /$ week and increased stepwise to $15.0 \mathrm{mg} /$ week in 12 weeks. Synovial biopsy specimens were taken before initiation of treatment and after 112 days of treatment from the same joint.

Fifteen patients who were DMARD naïve for at least 28 days started receiving leflunomide (LEF) after the first arthroscopy, ${ }^{7}$ at a loading dose of $100 \mathrm{mg}$ /day during the first 3 days and then $20 \mathrm{mg} /$ day thereafter. Synovial biopsy specimens were obtained before initiation of treatment and after 112 days of treatment from the same joint.

Ten patients who were receiving stable DMARD treatment (MTX, sulfasalazine, hydroxychloroquine, LEF, or a combination of these drugs) for at least 28 days were given 2 weeks' oral treatment of prednisolone at $60 \mathrm{mg} /$ day for 7 days followed by $40 \mathrm{mg} /$ day for another 7 days. ${ }^{3}$ Before treatment and at 2 weeks synovial biopsy specimens were taken from the same joint.

Infliximab treatment was started in 20 patients. These patients were receiving stable MTX for at least 28 days before infliximab treatment and stable prednisone was allowed at $\leqslant 10 \mathrm{mg} /$ day. Patients were dosed with $3 \mathrm{mg} / \mathrm{kg}$ infliximab on day 1 (directly after the first arthroscopy) and on day $15 .^{8}$ Arthroscopies were performed before initiation of treatment and, on average, after 28 days.

Ten patients with active RA who were receiving stable DMARD treatment for at least 28 days were treated with a specific CCRl antagonist. ${ }^{9}$ Patients were allowed to use stable low dose prednisone $\leqslant 10 \mathrm{mg}$ /day. They underwent arthroscopy directly before and after 14 days of treatment.

Some of the above mentioned clinical trials were placebo controlled studies. ${ }^{389}$ Therefore this allowed us to include a control group of 18 patients who underwent serial synovial biopsies at different intervals while they were receiving stable DMARD treatment (mostly MTX). These patients received a placebo treatment as detailed in the referred studies.

\section{Arthroscopy}

Synovial tissue was obtained by arthroscopy under local anaesthesia in all patients at baseline (before treatment) and directly after completion of each treatment strategy. Arthroscopies, tissue sampling, and storage were performed according to standardised procedures, as described previously in detail. ${ }^{7}$

\section{Immunohistochemistry}

Synovial tissue sections were stained with a monoclonal mouse-antihuman anti-CD68 antibody (EBMll; Dako, Glostrup, Denmark). Sections with non-assessable tissue, defined by the absence of an intimal lining layer, were omitted before analysis. For control sections, the primary antibodies were omitted or irrelevant isotype matched mouse antibodies were applied. Staining was performed according to a three step immunoperoxidase method as previously described in detail. ${ }^{10}$

\section{Digital image analysis}

Stained slides were evaluated by computer assisted image analysis. All sections were coded and analysed in a random order by an independent observer who was unaware of the clinical data, as described previously. ${ }^{11}$ For each patient the change in the number of total positive cells per square millimetre ST was calculated for sublining macrophages, and intimal macrophages were also evaluated.

\section{Statistical analysis}

Mean differences between independent groups were determined by one way analysis of variance and the independent samples $t$ test; significant differences were confirmed by nonparametric tests. The association between clinical measurements and the immunohistochemical results was quantified using Pearson's correlation coefficient. The immunohistochemical factors with significant correlation coefficients $(p<0.05)$ were entered into a linear regression analysis, testing for variables capable of explaining clinical response. The immunohistochemical markers were assigned as the independent variable. The probability of a significant association between the independent and dependent variables was defined as $\mathrm{p}<0.05$.

Standardised response means (SRMs) of the clinical scores and immunohistochemical scores were calculated to evaluate the ability of these measurements to detect changes over time in the different study groups. The SRM is the mean change in a score in a defined period of time divided by the standard deviation of the change in that score. An SRM of $>0.8$ is considered high, representing a change of at least four fifths of a standard deviation of the change in the score. An SRM of 0.5 is defined as having a moderate potential to detect changes, and an SRM of 0.2 as having low potential. ${ }^{12}$

\section{RESULTS}

\section{Clinical features}

Eighty eight patients were included and analysed in this study. Table 1 shows their baseline disease activity and treatment characteristics. All patients had active disease at baseline as measured by the DAS28 (mean (SEM) 6.02 (0.11)). On average, there were no differences in age, sex, and disease duration between the different subgroups; for further demographic and clinical characteristics we refer to

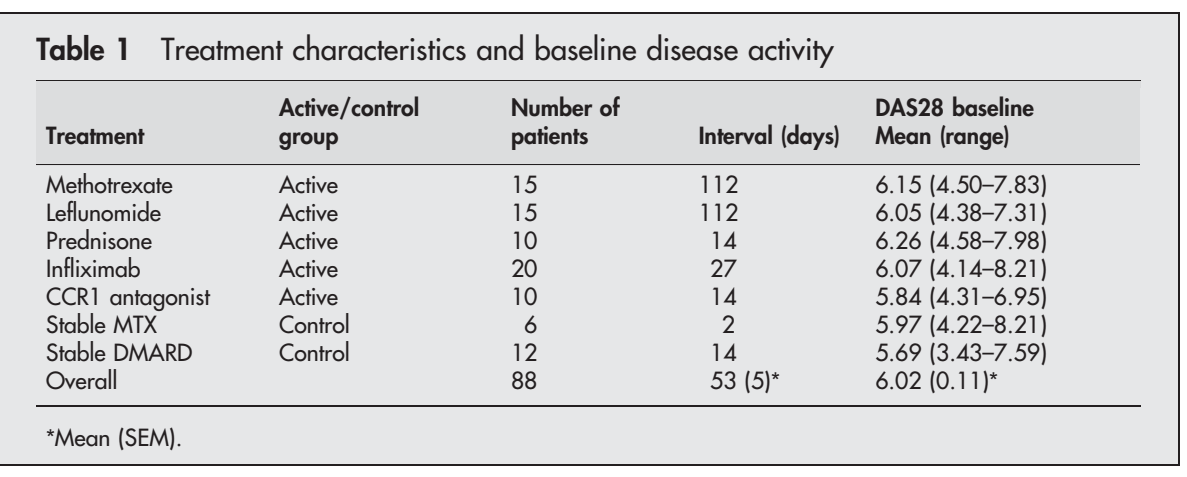


Table 2 Mean (SEM) change in DAS28, mean (SEM) change in the number of intimal lining CD68+ macrophages, mean (SEM) change in the number of sublining CD68+ macrophages, and the mean percentage change in sublining CD68+ macrophages compared with baseline for each substudy

\begin{tabular}{lllll}
\hline & $\begin{array}{l}\text { Change in the } \\
\text { number of intimal } \\
\text { lining CD68+ } \\
\text { macrophages } \\
\text { Mean (SEM) }\end{array}$ & $\begin{array}{l}\text { Change in the } \\
\text { number of } \\
\text { sublining CD68+ } \\
\text { macrophages } \\
\text { Mean (SEM) }\end{array}$ & $\begin{array}{l}\text { Change for } \\
\text { sublining CD68+ } \\
\text { macrophages } \\
\text { Mean \% }\end{array}$ & $\begin{array}{l}\text { Change in } \\
\text { DAS28 } \\
\text { Mean (SEM) }\end{array}$ \\
$\begin{array}{l}\text { Treatment } \\
\text { (No; interval) }\end{array}$ & $-35(46)$ & $-492(89)$ & -51 & $-2.15(0.40)$ \\
\hline Prednisolone start $(10 ; 14)$ & $-100(30)$ & $-275(84)$ & -47 & $-1.39(0.28)$ \\
Infliximab (Remicade) $(20 ; 28)$ & $-28(17)$ & $-286(112)$ & -38 & $-1.29(0.31)$ \\
Leflunomide start $(15 ; 112)$ & $-44(17)$ & $-292(106)$ & -41 & $-1.36(0.25)$ \\
Methotrexate start $(15 ; 112)$ & $-192(81)$ & $-338(131)$ & -44 & $-0.72(0.27)$ \\
CCR1 antagonist $(10 ; 14)$ & $+40(38)$ & $+152(107)$ & +13 & $-0.23(0.10)$ \\
Stable DMARD (12; 14) & $-71(29)$ & $+26(158)$ & +22 & $+0.07(0.28)$ \\
Stable MTX (6; 2) & $-76(17)$ & $-321(46)$ & -44 & $-1.37(0.14)$ \\
Active treatment grouped (70; 53) & $+3(29)$ & $+110(87)$ & +17 & $-0.13(0.12)$ \\
Controls grouped (18; 10) & & & & \\
\hline
\end{tabular}

the published data of all subgroups. ${ }^{3-9}$ The 70 patients who started active treatment showed, on average, a significant change in the DAS28 of $-1.37(0.14)$ (mean (SEM)) after treatment $(\mathrm{p}<0.001)$, whereas the DAS28 remained the same in the 18 control patients (change in DAS28 $-0.13(0.12)$; table 2).

The number of good, moderate, and non-responders was calculated for all patients according to the DAS28 response criteria. ${ }^{13}$ In total, 11 patients fulfilled the criteria for good responders (that is, improvement $>1.2$ and DAS28 at end point $\leqslant 3.2$ ), 35 patients were moderate responders (that is, improvement $>0.6$ and $\leqslant 1.2$ and DAS28 at end point $\leqslant 5.1$, or improvement $>1.2$ and DAS28 at end point $>3.2$ ), and 42 patients were considered non-responders.

\section{Changes in sublining macrophages are associated with clinical improvement}

Table 2 shows the changes in macrophage numbers in the intimal lining layer and sublining as well as the percentage changes in sublining macrophages compared with baseline, in relationship to changes in the DAS28 for the various trials. There was a significant difference in the mean (SEM) change in the number of sublining macrophages between good responders $(-643(124))$, moderate responders $(-270(64))$, and non-responders (-95 (60)) (one way analysis of variance, $\mathrm{p}<0.0003$; between group differences were determined by $t$ tests and confirmed by non-parametric tests). The intimal macrophages tended to be decreased in all groups. There were no significant differences in the mean change from baseline between the three response groups for the number of intimal macrophages (fig 1).

Of interest, the mean change in the number of sublining macrophages for each substudy was highly correlated with the mean change in DAS28, according to the two tailed Pearson correlation coefficient (Pearson correlation 0.874, $\mathrm{p}<0.01$ ) (fig 2). There were no correlations between the change in intimal macrophages and the change in DAS28 (data not shown). Linear regression analysis, weighted for the number of patients in each substudy, showed that the mean change in sublining macrophages could significantly explain $76 \%$ of the variance in the mean change in DAS28 grouped for each substudy $(\mathrm{p}<0.02)$.

\section{Changes in sublining macrophages may predict active treatment}

To determine the sensitivity to change, SRMs of the changes after treatment were calculated. Figure 3 shows that the SRMs in individual substudies were high for both sublining macrophages and DAS28 after active treatment. When patients from all active treatment substudies were grouped
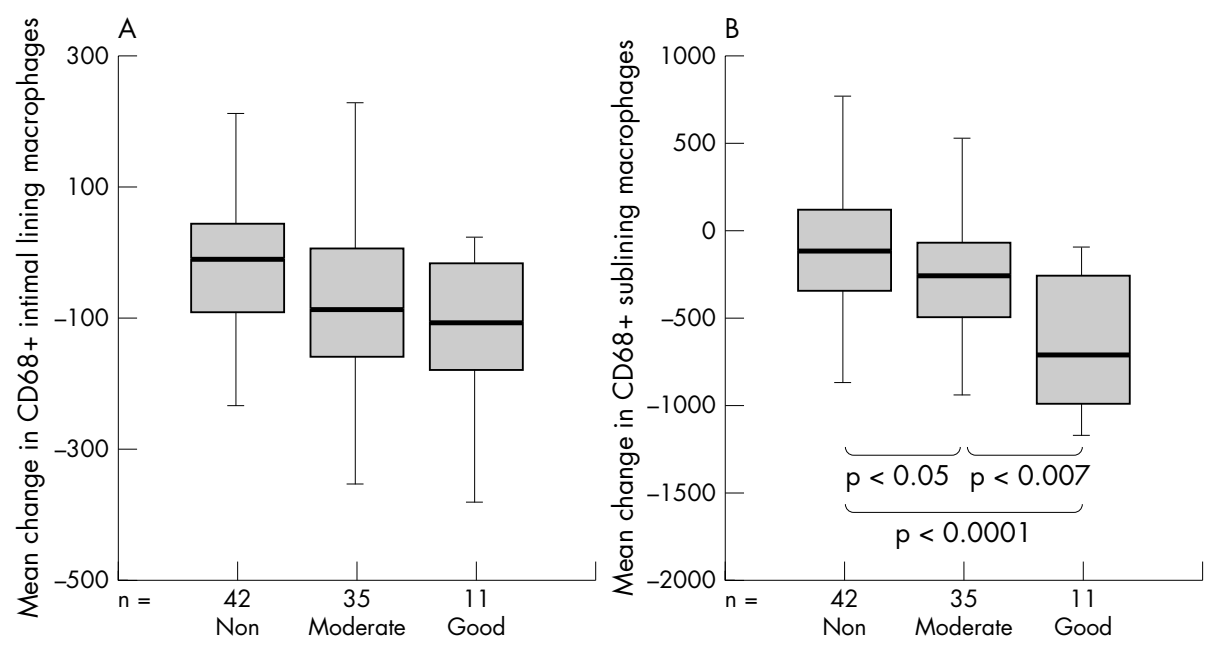

Figure 1 Mean values of the change compared with baseline in (A) the number of CD68+ macrophages in the intimal lining layer and (B) the synovial sublining for, respectively, non-responders, moderate responders, and good responders according to the DAS28 response criteria in the total study group. 


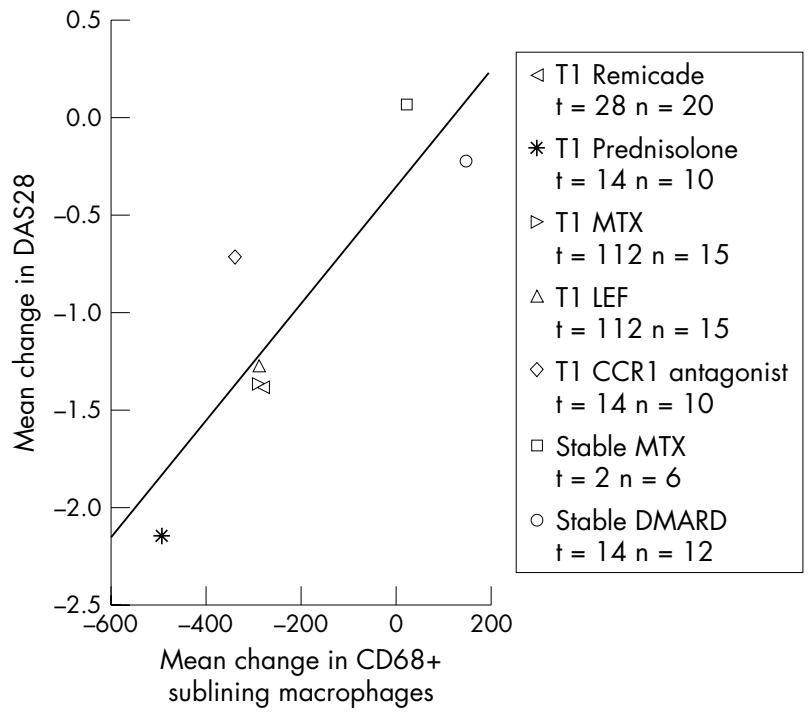

Figure 2 Correlation between the mean change for each substudy in the number of CD68+ sublining macrophages and the mean change in DAS28 ( $p<0.01$, Pearson correlation 0.874 , weighted linear regression $\mathrm{p}<0.02, R^{2}=0.755,95 \%$ confidence interval $(95 \% \mathrm{Cl}) 0.001$ to 0.005$)$. $t$, interval between the first and second measurement, $n$, number of patients; TI, treatment initiation.

$(n=70)$, the SRMs of the change in both the DAS28 and sublining macrophages were high (1.16 and 0.83 , respectively). In the control group where the second biopsy was performed after 2 days $(n=6)$ the SRM for both DAS28 and sublining macrophages was close to zero $(0.10$ and 0.07 , respectively). In the control group where the second biopsy was performed after 2 weeks $(n=12)$, the SRM for the DAS28 was -0.64 and the SRM for sublining macrophages 0.40 . When both control groups were grouped the SRM for the change in DAS28 was -0.23 and the SRM for the change in sublining macrophages was 0.30 , consistent with the notion that the biological marker is less susceptible to placebo effects or expectation bias than clinical evaluation.

\section{DISCUSSION}

The results of this study show that changes in numbers of synovial sublining macrophages correlate with clinical improvement independently of the therapeutic strategy. Furthermore, this study demonstrates that the change in the numbers of sublining macrophages may be used to explain clinical outcome. Of importance, the data indicate that the change in the number of sublining macrophages could be used as a sensitive biomarker to predict possible efficacy of a new antirheumatic treatment.

Previous work suggested an association between the number of synovial macrophages and joint destruction in RA. ${ }^{14}$ Moreover, analysis of the synovial cell infiltrate demonstrated a positive correlation between scores for local disease activity and the number of macrophages as well as expression of macrophage derived cytokines (tumour necrosis factor $\alpha(\mathrm{TNF} \alpha)$ and interleukin (IL) 6) in rheumatoid ST, suggesting that macrophage numbers are associated with clinical signs of inflammation. ${ }^{2}$ In keeping with this concept, macrophage numbers are increased in clinically affected joints compared with clinically non-affected joints of patients with RA. ${ }^{15}$ It appears likely that various pathogenetic mechanisms might lead to a final common pathway resulting in synovial macrophage activation. This may cause increased production of a variety of proinflammatory cytokines and chemokines, which play a part in the development of

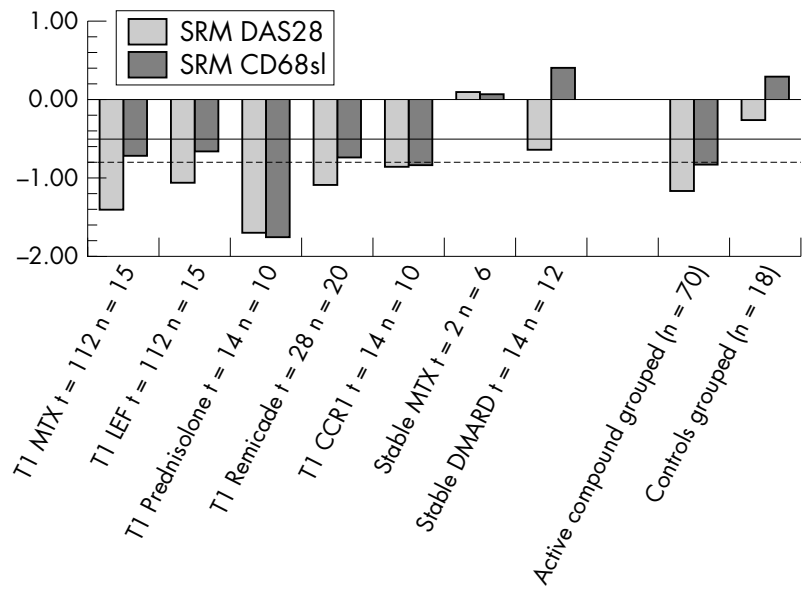

Figure 3 Standardised response mean (SRM) of the change in DAS28 (SRM DAS28) and the number of CD68+ macrophages in the sublining (SRM CD68sl) for the individual studies ( $t$, interval between the first and second measurement; $n$, number of patients, $\mathrm{Tl}$, treatment initiation) and grouped for patients who received initiation of an active compound $(n=70)$ and placebo $(n=18)$. The solid line indicates the 0.5 SRM cut off point (moderate), the dotted line indicates the 0.8 SRM cut off point (high).

symptoms like pain and swelling. ${ }^{16-18}$ The importance of macrophage derived cytokines for the clinical expression of the disease is underlined by the beneficial effect of strategies aimed at targeting TNF $\alpha$, ILl, and IL6. ${ }^{19-21}$ Of note, most of the macrophages in actively inflamed joints are localised by far in the synovial sublining rather than in the intimal lining layer. $^{22}$

The results presented here are consistent with previous studies examining the effects of treatment with DMARDs and biological agents at the site of inflammation. It has been shown that various effective agents like gold, sulfasalazine, MTX, and LEF can reduce macrophage infiltration in RA ST. ${ }^{723-25}$ Moreover, a predominant reduction in macrophage numbers of the synovial membrane has been reported in patients who achieved clinical remission as defined by the American College of Rheumatology criteria, induced by the use of various DMARDs. ${ }^{26}$ Similarly, treatment with antiTNF $\alpha$ antibodies and the ILl receptor antagonist reduced macrophage numbers. ${ }^{827} 28$ The same results were obtained using a specific CCRl antagonist. ${ }^{9}$

It should be noted that inflammatory cells other than macrophages may also be reduced after antirheumatic treatment, depending on the specific mechanism of action and the duration of treatment. Obviously, these specific cell types and their mediators of inflammation also need to be evaluated in studies focusing on the mechanism of action of targeted treatments. The immunohistological variables may correlate with each other to a certain extent. Recently, we conducted a study to provide a greater understanding of the changes in the ST alongside clinical response by using a known clinically effective treatment, prednisolone. ${ }^{3}$ The analysis model of covariance showed that clinically effective prednisolone treatment was particularly associated with a marked reduction in macrophage infiltration in the RA ST after 2 weeks of treatment. Comparable results were obtained after infliximab treatment. ${ }^{8}$

As a result of these observations, we investigated whether this biomarker might exhibit similar changes after different therapeutic regimens and after varying lengths of treatment. The results of this study show that this is the case. There is a highly significant correlation between changes in sublining macrophages and clinical improvement, independent of the specific treatments studied. The changes may be observed as 
early as 14 days after initiation of effective treatment, but treatment for more prolonged periods results in a more pronounced decrease in macrophage infiltration. Patients who are good, moderate, or non-responders according to the DAS28 response criteria differ significantly in the changes in the number of sublining macrophages. Additionally, it is possible to explain the change in DAS28 based upon the change in sublining macrophages, which implies a direct relationship between macrophages and clinical measures of disease activity.

Moreover, we investigated the sensitivity to change of this biomarker after active treatment or placebo. According to the SRM, the sensitivity to change after active treatment is good for both the DAS28 and sublining macrophages. The SRMs calculated for changes in DAS28 and sublining macrophages after placebo treatment suggest that the biological marker may be less susceptible to placebo effects or expectation bias than clinical evaluation. This might be explained by the subjective components included in clinical measures of disease activity. ${ }^{29}$ This notion is supported by a previous study in an independent patient cohort using semiquantitative analysis, showing unaltered immunohistological scores in serial synovial biopsy specimens obtained after placebo treatment. $^{30}$

In conclusion, the results of this study indicate that synovial sublining macrophages might be used as a biomarker for the evaluation of new antirheumatic treatments. In addition to providing insight into the mechanism of action of treatment, this approach may help to screen for possible efficacy.

\section{ACKNOWLEDGEMENTS}

Drs Gerlag, Kraan, and Smeets received support from the Dutch Arthritis Foundation.

\section{Authors' affiliations}

J J Haringman, D M Gerlag, T J M Smeets, M C Kraan, P P Tak, Division of Clinical Immunology and Rheumatology, Academic Medical Centre/ University of Amsterdam, The Netherlands

A H Zwinderman, Department of Clinical Epidemiology and Biostatistics, Academic Medical Centre/University of Amsterdam, The Netherlands

D Baeten, Department of Rheumatology, Ghent University Hospital, Belgium

I B McInnes, Centre for Rheumatic Diseases, University of Glasgow, Scotland, UK

B Bresnihan, Rheumatology Department, St Vincent's University Hospital, Dublin, Ireland

\section{REFERENCES}

1 Bresnihan B, Tak PP, Emery P, Klareskog L, Breedveld F. Synovial biopsy in arthritis research: five years of concerted European collaboration. Ann Rheum Dis 2000;59:506-1 1 .

2 Tak PP, Smeets TJ, Daha MR, Kluin PM, Meijers KA, Brand R, et al. Analysis of the synovial cell infiltrate in early rheumatoid synovial tissue in relation to local disease activity. Arthritis Rheum 1997;40:217-25.

3 Gerlag DM, Haringman JJ, Smeets TJM, Zwinderman AH, Kraan MC, Laud PJ et al. Effects of oral prednisolone on biomarkers in synovial tissue and clinica improvement in rheumatoid arthritis. Arthritis Rheum 2004:50:3783-91.

4 Boers M, Verhoeven AC, Markusse HM, van de Laar MA, Westhovens R, van Denderen JC, et al. Randomised comparison of combined step-down prednisolone, methotrexate and sulphasalazine with sulphasalazine alone in early rheumatoid arthritis. Lancet 1997;350:309-18.

5 Arnett FC, Edworthy SM, Bloch DA, McShane DJ, Fries JF, Cooper NS, et al. The American Rheumatism Association 1987 revised criteria for the classification of rheumatoid arthritis. Arthritis Rheum 1988;31:315-24.
6 Prevoo ML, van 't Hof MA, Kuper HH, van Leeuwen MA, van de Putte LB, van Riel PL. Modified disease activity scores that include twenty-eight-joint counts. Development and validation in a prospective longitudinal study of patients with rheumatoid arthritis. Arthritis Rheum 1995;38:44-8.

7 Kraan MC, Reece RJ, Barg EC, Smeets TJ, Farnell J, Rosenburg R, et al. Modulation of inflammation and metalloproteinase expression in synovial tissue by leflunomide and methotrexate in patients with active rheumatoid arthritis. Findings in a prospective, randomized, double-blind, parallel-design clinical trial in thirty-nine patients at two centers. Arthritis Rheum 2000;43:1820-30

8 Smeets TJ, Kraan MC, van Loon ME, Tak PP. Tumor necrosis factor alpha blockade reduces the synovial cell infiltrate early after initiation of treatment, but apparently not by induction of apoptosis in synovial tissue. Arthritis Rheum 2003:48:2155-62.

9 Haringman JJ, Kraan MC, Smeets TJ, Zwinderman KH, Tak PP. Chemokine blockade and chronic inflammatory disease: proof of concept in patients with rheumatoid arthritis. Ann Rheum Dis 2003;62:715-21.

10 Tak PP, van der Lubbe PA, Cauli A, Daha MR, Smeets TJ, Kluin PM, et al. Reduction of synovial inflammation after anti-CD4 monoclonal antibody treatment in early rheumatoid arthritis. Arthritis Rheum 1995;38:1457-65.

11 Kraan MC, Haringman JJ, Ahern MJ, Breedveld FC, Smith MD, Tak PP. Quantification of the cell infiltrate in synovial tissue by digital image analysis. Rheumatology (Oxford) 2000;39:43-9.

12 Kazis LE, Anderson JJ, Meenan RF. Effect sizes for interpreting changes in health status. Med Care 1989;27(suppl):S178-89.

13 van Riel PL, van Gestel AM, van de Putte LB. Development and validation of response criteria in rheumatoid arthritis: steps towards an international consensus on prognostic markers. $\mathrm{Br} J$ Rheumatol 1996:35(suppl 2):4-7.

14 Mulherin D, Fitzgerald O, Bresnihan B. Synovial tissue macrophage populations and articular damage in rheumatoid arthritis. Arthritis Rheum 1996;39:115-24

15 Kraan MC, Versendaal H, Jonker M, Bresnihan B, Post WJ, Hart BA, et al. Asymptomatic synovitis precedes clinically manifest arthritis. Arthritis Rheum 1998;41:1481-8.

16 Kinne RW, Brauer R, Stuhlmuller B, Palombo-Kinne E, Burmester GR Macrophages in rheumatoid arthritis. Arthritis Res 2000;2:189-202.

17 Vervoordeldonk MJ, Tak PP. Cytokines in rheumatoid arthritis. Curr Rheumatol Rep 2002;4:208-17.

18 Firestein GS. Evolving concepts of rheumatoid arthritis. Nature 2003;423:356-61

19 Feldmann M, Maini RN. Anti-TNF alpha therapy of rheumatoid arthritis: what have we learned? Annu Rev Immunol 2001;19:163-96.

20 Dayer JM, Bresnihan B. Targeting interleukin-1 in the treatment of rheumatoid arthritis. Arthritis Rheum 2002;46:574-8.

21 Choy EH, Isenberg DA, Garrood T, Farrow S, loannou Y, Bird H, et al. Therapeutic benefit of blocking interleukin- 6 activity with an anti-interleukin- 6 receptor monoclonal antibody in rheumatoid arthritis: a randomized, doubleblind, placebo-controlled, dose-escalation trial. Arthritis Rheum 2002;46:3143-50.

22 Smeets TJ, Barg EC, Kraan MC, Smith MD, Breedveld FC, Tak PP. Analysis of the cell infiltrate and expression of proinflammatory cytokines and matrix metalloproteinases in arthroscopic synovial biopsies: comparison with synovial samples from patients with end stage, destructive rheumatoid arthritis. Ann Rheum Dis 2003;62:635-8.

23 Yanni G, Nabil M, Farahat MR, Poston RN, Panayi GS. Intramuscular gold decreases cytokine expression and macrophage numbers in the rheumatoid synovial membrane. Ann Rheum Dis 1994;53:315-22.

24 Pettit AR, Weedon H, Ahern M, Zehntner S, Frazer IH, Slavotinek J, et al. Association of clinical, radiological and synovial immunopathological responses to anti-rheumatic treatment in rheumatoid arthritis. Rheumatology (Oxford) 2001:40:1243-55.

25 Dolhain RJ, Tak PP, Dijkmans BA, De Kuiper P, Breedveld FC, Miltenburg AM. Methotrexate reduces inflammatory cell numbers, expression of monokines and of adhesion molecules in synovial tissue of patients with rheumatoid arthritis. Br J Rheumatol 1998;37:502-8.

26 Smith MD, Kraan MC, Slavotinek J, Au V, Weedon H, Parker A, et al. Treatment-induced remission in rheumatoid arthritis patients is characterized by a reduction in macrophage content of synovial biopsies. Rheumatology (Oxford) 2001;40:367-74

27 Taylor PC, Peters AM, Paleolog E, Chapman PT, Elliott MJ, McCloskey R, et al. Reduction of chemokine levels and leukocyte traffic to joints by tumor necrosis factor alpha blockade in patients with rheumatoid arthritis. Arthritis Rheum 2000;43:38-47.

28 Cunnane G, Madigan A, Murphy E, Fitzgerald O, Bresnihan B. The effects of treatment with interleukin-1 receptor antagonist on the inflamed synovial membrane in rheumatoid arthritis. Rheumatology (Oxford) 2001;40:62-9.

29 Epstein WV. Expectation bias in rheumatoid arthritis clinical trials. The antiCD4 monoclonal antibody experience. Arthritis Rheum 1996;39:1773-80.

30 Smeets TJ, Kraan MC, Versendaal J, Breedveld FC, Tak PP. Analysis of serial synovial biopsies in patients with rheumatoid arthritis: description of a control group without clinical improvement after treatment with interleukin 10 or placebo. J Rheumatol 1999;26:2089-93. 